\title{
Castration, androgens, and dominance status in the rat'
}

\author{
JANE STEWART AND TIBOR PALFAI
}

SIR GEORGE WILLIAMS UNIVERSITY

The effects of castration and androgen replacement on dominance status were studied in 22 male rats by the method of paired competitive encounters. The dominance hierarchy existing before castration became disrupted after castration. It was reinstated by daily doses of $1 \mu \mathrm{gm}$ testosterone proprionate; a higher daily dose of $50 \mu$ gm increased further the correlation between the initial hierarchy and the post-replacement hierarchy. It is suggested that the differential effects of identical amounts of androgens on dominance status arise from individual differences in the complexity and development of the neural structures involved in aggressive behavior.

Castration is known to decrease aggressiveness in male animals and androgen administration to increase it, but the mechanism by which these hormonal changes bring about alterations in aggressiveness is not understood (Beach, 1948; Bindra, 1959). The present experiment was designed to answer two questions bearing on the mechanism of androgenic control of aggression. First, does the administration of androgens in a dose too small to produce morphologic changes in peripheral organs produce a change in aggressiveness? Second, what is the effect of the administration of the same amount of androgens on the relative aggressiveness of animals differing in their initial level of aggressiveness? We approached these questions by studying, in the rat, the effect of castration and androgen injections on a dominance hierarchy established through the method of paired competitive encounters.

Subjects

Twenty-two male hooded rats, ranging in weight from 260-340 $\mathrm{gm}$ were used. The rats were divided into two groups of 11 animals each and were housed in four living cages: Experimental group: cage 1, rats $1-5$, cage 2 , rats $6-11$; Control group: cage 3 , rats $1-5$, cage 4 , rats $6-11$. The animals were maintained on a $22-1 / 4 \mathrm{hr}$. food-deprivation schedule and were allowed free access to wet mash for $45 \mathrm{~min}$. each day.

\section{Apparafus}

The test apparatus was a $48 \times 14 \times 14$ in. plywood box divided into three compartments. The two end compartments (start-boxes) were $9 \times 14 \times 14$ in. and were separated from the main area by guillotine doors. In the center of the main area was a round food container, 2 in. high and $1-3 / 4$ in. in diameter. Only one animal could eat from it at any one time.

\section{Procedure}

Practice Trials. In these trials animals were run indiviciually. The animal was placed in one of the start boxes, both doors were raised simultaneously, and the animal was allowed to eat from the food container for 2 min. It was then placed on a stand until every animal in the group had received one practice trial. All animals were returned to their home cages and given food for $45 \mathrm{~min}$. This procedure was continued from Day 1 to Day 5.

Dominance Testing. From Day 6 to Day 10 dominance tests were carried out. Each animal competed for food with every other animal in the test apparatus. Each competition lasted $2 \mathrm{~min}$. No animal competed more than three times daily. In the competitive situation one animal was placed in each of the start-boxes. The doors were raised simultaneously, and, the moment either of the rats reached the food two stopwatches were started. One stopwatch timed the 2-min. session. The second, cumulative, stopwatch was stopped when the second rat gained possession of the food and started again when the first rat regained possession. The animal which spent the greater proportion of the 2-min. test period in possession of the food container was considered the "winner." The animal which obtained the greatest number of wins over all pairings was ranked first on the dominance hierarchy. In cases where two animals had an equal number of wins, the total time in possession of food over all trials was used to differentiate the ranks.

Operative Procedure. On Day 11, the experimental animals were castrated under ether anesthesia. Animals in the control group were also anesthetized, but no operation was performed. During operation the least dominant animal in the experimental group died under the anesthetic. For this reason the least dominant animal was removed from the control group at the same time. All animals were allowed two weeks for recovery; during this time the animals lived, on ad lib diet, in their home cages. On Day 22, the 22-1/4 hr. food-deprivation schedule was reintroduced and continued throughout dominance retesting.

Dominance Retesting. From Day 26 to Day 29 both groups were retested for dominance as before.

Hormonal Replacement. On Days 30 to 42 the experimental animals were given daily subcutaneous injections of $1 \mu \mathrm{gm}$ testosterone proprionate dissolved in $0.2 \mathrm{cc}$ sesame oil. During this same period the control animals received injections of the sesame oil only. Finally, on Days 43 to 55 in the experimental group the dose of testosterone proprionate was raised to $50 \mu \mathrm{gm}$ daily.

Dominance Retesting. The experimental group was retested for dominance once during the $1 \mu \mathrm{gm}$ testosterone treatment (Days 38 to 42 ) and once during the 
Tahle 1. Ranks of animals after each dominance testing period.

\begin{tabular}{lcccc}
$\begin{array}{c}\text { Experimental Group } \\
\text { Subject }\end{array}$ & $\begin{array}{c}\text { Post } \\
\text { Initial }\end{array}$ & $\begin{array}{c}\text { After } 1 \mu \mathrm{gm} \\
\text { Costrathy } \\
\text { testesterone } \\
\text { treatment }\end{array}$ & $\begin{array}{c}\text { After } 50 \mu \mathrm{gm} \\
\text { testosterone } \\
\text { treatment }\end{array}$ \\
\hline VIII & 1 & 3 & 1 & 1 \\
XI & 2 & 5 & 2 & 4 \\
IX & 3 & 4 & 5 & 2 \\
VII & 4 & 6 & 3 & 5 \\
II & 5 & 1 & 7 & 3 \\
X & 6 & 8 & 6 & 6 \\
I & 7 & 9 & 4 & 8 \\
IV & 8 & 7 & 9 & 7 \\
III & 9 & 2 & 8 & 9 \\
V & 10 & 10 & 10 & 10 \\
\hline
\end{tabular}

\begin{tabular}{lccc}
$\begin{array}{l}\text { Control Group } \\
\text { Subject }\end{array}$ & $\begin{array}{c}\text { Initial } \\
\text { Hierarchy }\end{array}$ & $\begin{array}{c}\text { Post } \\
\text { Anesthetic }\end{array}$ & $\begin{array}{c}\text { Post } \\
\text { Vehicle }\end{array}$ \\
\hline II & 1 & 1 & 1 \\
III & 2 & 2 & 4 \\
VIII & 3 & 3 & 3 \\
XI & 4 & 7 & 6 \\
IX & 5 & 6 & 2 \\
VI & 6 & 5 & 5 \\
V & 7 & 4 & 7 \\
X & 8 & 8 & 9 \\
IV & 9 & 10 & 10 \\
VII & 10 & 9 & 8 \\
\hline
\end{tabular}

$50 \mu \mathrm{gm}$ treatment (Days 51 to 55 ). After each five days of retesting the animals were allowed four days of ad libitum feeding and then were reintroduced to the 22-1/4 hr. schedule four days before the next retesting days. The control group was tested for the last time from Days 38 to 42 .

\section{Results}

After every dominance testing period the animals in each group were ranked according to the number of wins. The ranks obtained are shown in Table 1. Spearman rank correlation coefficients were obtained between the hierarchies established after each dominance testing period. For 10 cases the value of $\mathrm{r}$ needed for significance at the .02 level (two-tailed test) is 0.746 . In the control group, the dominance hierarchy remained highly stable throughout the experiment; the correlations between the initial hierarchy and those obtained at the two later testings were 0.867 and 0.855 . After castration all the animals in the experimental group appeared to be less aggressive in the competitive encounters, and, as can be seen, the initial hierarchy was disrupted. The correlation between the initial hierarchy and that obtained after castration was positive, but not significant $(r=0.442)$. However, after replacement therapy, even at the lower dose, the hierarchy correlated significantly with the initial hierarchy ( $r=$ 0.879 ). The higher dose increased the correlation slightly $(r=0.927)$.

At no time was there a significant positive correla- tion between body weight and dominance status; the only time that a positive correlation neared a significant level was post-castration and pre-androgen in the experimental group $(r=0.552)$.

\section{Discussion}

The results show that castration disrupted the hierarchy established in the pre-castration state. The fact that some animals achieved a higher place on the hierarchy than they had before castration should not be taken to indicate that some animals become more aggressive after castration. All animals were observed to be less aggressive in their encounters and the upset in the hierarchy reflects rather a lack of vigor and consistency in their behavior.

The initial hierarchy was reinstated by $1 \mu \mathrm{gm}$ injections, an amount of androgen probably well below normal blood levels (Albert, 1961) and well below blood levels needed to restore accessory sex organs after castration (Moore, 1939). This fact suggests that androgens can affect aggressive behavior by acting directly on the central nervous system. Since each animal received exactly the same amount of androgen it would appear that absolute differences in gonadal output are not responsible for differences in aggressiveness. Thus we conclude that individual differences in aggressiveness are due to differences in the central nervous system. In view of the fact that factors other than humoral can lead to individual differences in aggressive behavior and dominance (Hutchinson, Azrin, \& Ulrich, 1966; Uyeno, 1960) we suggest that the source of difference could be in the pervasiveness or "strength" of the neural structures mediating aggressive activities. If the normally more aggressive or dominant animals are assumed to have more complex and developed neural structures involved in aggressive activities, then the minimal amount of hormone necessary to affect aggressive behavior would have a greater effect in these animals.

\section{References}

Albert, A. The mammalian testis. In W. C. Young and G. W. Corner (Eds.), Sex and internal secretions. (3rd ed.) Baltimore: Williams and Wilkins, 1961.

Beach, F. A. Hormones and behavior. New York: Hoeber, 1948. Bindra, D. Motivation: a systematic reinterpretation. New York: Ronald, 1959

Hutchinson, R. R., Azrin, N. H., \& Ulrich, R. E. Effects of age and related factors on reflexive aggression. J. comp. physiol. Psychol., 1965, 59, 365-369.

Moore, C. R. Biology of the testes. In E. Allen, C. H. Denforth and E. A. Doisey (Eds.), Sex and internal secretions. (2nd ed.) Baltimore: Williams and Wilkins, 1939.

Uyeno, E. T. Hereditary and environmental aspects of dominant behavior in the albino rat. J. comp. physiol. Psychol., 1960, $53,138-141$.

\section{Note}

1. This research was supported by the National Research Council of Canada (Grant No. APA-156). 